\title{
A Hybrid Projection Algorithm for Finding Solutions of Mixed Equilibrium Problem and Variational Inequality Problem
}

\author{
Filomena Cianciaruso, ${ }^{1}$ Giuseppe Marino, ${ }^{1}$ \\ Luigi Muglia, ${ }^{1}$ and Yonghong Yao ${ }^{2}$ \\ ${ }^{1}$ Dipartimento di Matematica, Universitá della Calabria, 87036 Arcavacata di Rende (CS), Italy \\ ${ }^{2}$ Department of Mathematics, Tianjin Polytechnic University, Tianjin 300160, China
}

Correspondence should be addressed to Giuseppe Marino, gmarino@unical.it

Received 3 June 2009; Accepted 16 September 2009

Academic Editor: Mohamed A. Khamsi

Copyright (c) 2010 Filomena Cianciaruso et al. This is an open access article distributed under the Creative Commons Attribution License, which permits unrestricted use, distribution, and reproduction in any medium, provided the original work is properly cited.

We propose a modified hybrid projection algorithm to approximate a common fixed point of a $k$-strict pseudocontraction and of two sequences of nonexpansive mappings. We prove a strong convergence theorem of the proposed method and we obtain, as a particular case, approximation of solutions of systems of two equilibrium problems.

\section{Introduction}

In this paper, we define an iterative method to approximate a common fixed point of a $k$ strict pseudocontraction and of two sequences of nonexpansive mappings generated by two sequences of firmly nonexpansive mappings and two nonlinear mappings. Let us recall from [1] that the $k$-strict pseudocontractions in Hilbert spaces were introduced by Browder and Petryshyn in [2].

Definition 1.1. $S: C \rightarrow C$ is said to be $k$-strict pseudocontractive if there exists $k \in[0,1[$ such that

$$
\|S x-S y\|^{2} \leq\|x-y\|^{2}+k\|(I-S) x-(I-S) y\|^{2}, \quad \forall x, y \in C .
$$

The iterative approximation problems for nonexpansive mappings, asymptotically nonexpansive mappings, and asymptotically pseudocontractive mappings were studied extensively by Browder [3], Goebel and Kirk [4], Kirk [5], Liu [6], Schu [7], and Xu [8,9] 
in the setting of Hilbert spaces or uniformly convex Banach spaces. Although nonexpansive mappings are 0 -strict pseudocontractions, iterative methods for $k$-strict pseudocontractions are far less developed than those for nonexpansive mappings. The reason, probably, is that the second term appearing in the previous definition impedes the convergence analysis for iterative algorithms used to find a fixed point of the $k$-strict pseudocontraction $S$. However, $k$-strict pseudocontractions have more powerful applications than nonexpansive mappings do in solving inverse problems. In the recent years the study of iterative methods like Mann's like methods and CQ-methods has been extensively studied by many authors [1, 10-13] and the references therein.

If $C$ is a closed and convex subset of a Hilbert space $H$ and $F: C \times C \rightarrow \mathbb{R}$ is a bi-function we call equilibrium problem

$$
\text { Find } \bar{x} \in C \quad \text { s.t. } F(\bar{x}, y) \geq 0, \quad \forall y \in C \text {, }
$$

and we will indicate the set of solutions with $E P(F)$.

If $A: C \rightarrow H$ is a nonlinear mapping, we can choose $F(x, y)=\langle A x, y-x\rangle$, so an equilibrium point (i.e., a point of the set $E P(F)$ ) is a solution of variational inequality problem (VIP)

$$
\text { Find } \bar{x} \in C \quad \text { s.t. }\langle A \bar{x}, y-\bar{x}\rangle \geq 0, \quad \forall y \in C \text {. }
$$

We will indicate with $\operatorname{VI}(C, A)$ the set of solutions of VIP.

The equilibrium problems, in its various forms, found application in optimization problems, fixed point problems, convex minimization problems; in other words, equilibrium problems are a unified model for problems arising in physics, engineering, economics, and so on (see [10]).

As in the case of nonexpansive mappings, also in the case of $k$-strict pseudocontraction mappings, in the recent years many papers concern the convergence of iterative methods to a solutions of variational inequality problems or equilibrium problems; see example for, [10, 14-18].

Here we prove a strong convergence theorem of the proposed method and we obtain, as a particular case, approximation of solutions of systems of two equilibrium problems.

\section{Preliminaries}

Let $H$ be a real Hilbert space and let $C$ be a nonempty closed convex subset of $H$. We denote by $P_{C}$ the metric projection of $H$ onto $C$. It is well known [19] that

$$
\left\langle x-P_{C}(x), P_{C}(x)-y\right\rangle \geq 0, \quad \forall x \in H \text { and } y \in C .
$$

Lemma 2.1. (see [20]) Let $X$ be a Banach space with weakly sequentially continuous duality mapping $J$, and suppose that $\left(x_{n}\right)_{n \in \mathbb{N}}$ converges weakly to $x_{0} \in X$, then for any $x \in X$,

$$
\liminf _{n \rightarrow \infty}\left\|x_{n}-x_{0}\right\| \leq \liminf _{n \rightarrow \infty}\left\|x_{n}-x\right\| .
$$

Moreover if $\mathrm{X}$ is uniformly convex, equality holds in (2.2) if and only if $x_{0}=x$. 
Fixed Point Theory and Applications

Recall that a point $u \in C$ is a solution of a VIP if and only if $u=P_{C}(I-\lambda A) u \quad \forall \lambda>0, \quad$ that is, $u \in V I(C, A) \Longleftrightarrow u \in \operatorname{Fix}\left(P_{C}(I-\lambda A)\right), \quad \forall \lambda>0$.

Definition 2.2. An operator $A: C \rightarrow H$ is said to be $\alpha$-inverse strongly monotone operator if there exists a constant $\alpha>0$ such that

$$
\langle A x-A y, x-y\rangle \geq \alpha\|A x-A y\|^{2} \quad \forall x, y \in C .
$$

If $\alpha=1$ we say that $A$ is firmly nonexpansive. Note that every $\alpha$-inverse strongly monotone operator is also $1 / \alpha$ Lipschitz continuous (see [21]).

Lemma 2.3. (see [2]). Let $C$ be a nonempty closed convex subset of a real Hilbert space $H$ and let $S: C \rightarrow C$ be a $k$-strict pseudocontractive mapping. Then $S_{t}:=t I+(1-t) S$ with $t \in[k, 1[$ is a nonexpansive mapping with $\operatorname{Fix}\left(S_{t}\right)=\operatorname{Fix}(S)$.

\section{Main Theorem}

Theorem 3.1. Let $C$ be a closed convex subset of a real Hilbert space H. Let

(i) A be an $\alpha$-inverse strongly monotone mapping of $C$ into $H$,

(ii) $B$ a $\beta$-inverse strongly monotone mapping of $C$ into $H$,

(iii) $\left(T_{n}\right)_{n \in \mathbb{N}}$ and $\left(V_{n}\right)_{n \in \mathbb{N}}$ two sequences of firlmy nonexpansive mappings from $C$ to $H$.

Let $S: C \rightarrow C$ be a $k$-strict pseudocontraction $\operatorname{Fix}(S) \neq \emptyset$.

Set $S_{k}=k I+(1-k) S$ and let us define the sequence $\left(x_{n}\right)_{n \in \mathbb{N}}$ as follows:

$$
\begin{gathered}
x_{1} \in C, \\
C_{1}=C, \\
u_{n}=T_{n}\left(I-r_{n} A\right) x_{n} \\
z_{n}=V_{n}\left(I-\lambda_{n} B\right) u_{n}, \\
y_{n}=\alpha_{n} x_{n}+\left(1-\alpha_{n}\right) S_{k} z_{n}, \\
C_{n+1}=\left\{w \in C_{n}:\left\|y_{n}-w\right\| \leq\left\|x_{n}-w\right\|\right\}, \\
x_{n+1}=P_{C_{n+1}} x_{1}, \quad \forall n \in N,
\end{gathered}
$$

where

(i) $\left(\alpha_{n}\right)_{n \in \mathbb{N}} \subset[0, a]$ with $a<1$;

(ii) $\left(\lambda_{n}\right)_{n \in \mathbb{N}} \subset[b, c] \subset(0,2 \beta)$;

(iii) $\left(r_{n}\right)_{n \in \mathbb{N}} \subset[d, e] \subset(0,2 \alpha)$. 
Moreover suppose that

(i) $F:=\operatorname{Fix}(S) \cap \cap_{n} \operatorname{Fix}\left(V_{n}\left(I-\lambda_{n} B\right)\right) \cap \cap_{n} \operatorname{Fix}\left(T_{n}\left(I-r_{n} A\right)\right) \neq \emptyset$;

(ii) $\left(T_{n}\left(I-r_{n} A\right)\right)_{n \in \mathbb{N}}$ pointwise converges in $C$ to an operator $R$ and $\left(V_{n}\left(I-\lambda_{n} B\right)\right)_{n \in \mathbb{N}}$ pointwise converges in $C$ to an operator $W$;

(iii) $\operatorname{Fix}(W)=\cap_{n} \operatorname{Fix}\left(V_{n}\left(I-\lambda_{n} B\right)\right)$ and $\operatorname{Fix}(R)=\cap_{n} \operatorname{Fix}\left(T_{n}\left(I-r_{n} A\right)\right)$.

Then $\left(x_{n}\right)_{n \in \mathbb{N}}$ strongly converges to $x^{*}=P_{F} x_{1}$.

Proof. We begin to observe that the mappings $T_{n}\left(I-r_{n} A\right)$ and $V_{n}\left(I-\lambda_{n} B\right)$ are nonexpansive for all $n \in \mathbb{N}$ since they are compositions of nonexpansive mappings (see [22, page 419]). As a rule, if $p \in F$

$$
\begin{aligned}
& \left\|u_{n}-p\right\|^{2} \leq\left\|x_{n}-p\right\|^{2}, \\
& \left\|z_{n}-p\right\|^{2} \leq\left\|u_{n}-p\right\|^{2} \leq\left\|x_{n}-p\right\|^{2} .
\end{aligned}
$$

Now we divide the proof in more steps.

Step 1. $C_{n}$ is closed and convex for each $n \in \mathbb{N}$.

Indeed $C_{n+1}$ is the intersection of $C_{n}$ with the half space

$$
\left\{w \in H:\left\langle w, x_{n}-y_{n}\right\rangle \leq L\right\}
$$

where $L=\left(\left\|x_{n}\right\|^{2}-\left\|y_{n}\right\|^{2}\right) / 2$.

Step 2. $F \subseteq C_{n}$ for each $n \in \mathbb{N}$.

For each $w \in F$ we have

$$
\begin{aligned}
\left\|y_{n}-w\right\| & =\left\|\alpha_{n} x_{n}+\left(1-\alpha_{n}\right) S_{k} z_{n}-w\right\| \\
& \leq \alpha_{n}\left\|x_{n}-w\right\|+\left(1-\alpha_{n}\right)\left\|z_{n}-w\right\| \\
& =\alpha_{n}\left\|x_{n}-w\right\|+\left(1-\alpha_{n}\right)\left\|V_{n}\left(I-\lambda_{n} B\right) u_{n}-w\right\| \\
& \leq \alpha_{n}\left\|x_{n}-w\right\|+\left(1-\alpha_{n}\right)\left\|u_{n}-w\right\| \\
& =\alpha_{n}\left\|x_{n}-w\right\|+\left(1-\alpha_{n}\right)\left\|T_{n}\left(I-r_{n} A\right) x_{n}-w\right\| \\
& \leq \alpha_{n}\left\|x_{n}-w\right\|+\left(1-\alpha_{n}\right)\left\|x_{n}-w\right\| \\
& =\left\|x_{n}-w\right\| .
\end{aligned}
$$

So the claim immediately follows by induction. 
Step 3. $\lim _{n \rightarrow+\infty}\left\|x_{n}-x_{1}\right\|$ exists and $\left(x_{n}\right)_{n \in \mathbb{N}}$ is asymptotically regular, that is, $\lim _{n \rightarrow+\infty} \| x_{n+1}-$ $x_{n} \|=0$.

Since $x_{n}=P_{C_{n}} x_{1}, x_{n+1}=P_{C_{n+1}} x_{1}$, and $C_{n+1} \subseteq C_{n}$, by (2.1) choosing $y=x_{n+1}, x=x_{1}$ and $C=C_{n}$, we have

$$
\begin{aligned}
0 & \leq\left\langle x_{1}-x_{n}, x_{n}-x_{n+1}\right\rangle \\
& =\left\langle x_{1}-x_{n}, x_{n}-x_{1}+x_{1}-x_{n+1}\right\rangle \\
& \leq-\left\|x_{1}-x_{n}\right\|^{2}+\left\|x_{1}-x_{n}\right\|\left\|x_{1}-x_{n+1}\right\|,
\end{aligned}
$$

that is, $\left\|x_{n}-x_{1}\right\| \leq\left\|x_{n+1}-x_{1}\right\|$.

By $x_{n}=P_{C_{n}} x_{1}$ and $F \subseteq C_{n}$, we have

$$
\left\|x_{1}-x_{n}\right\| \leq\left\|x_{1}-P_{F} x_{1}\right\|
$$

Then $\lim _{n \rightarrow+\infty}\left\|x_{n}-x_{1}\right\|$ exists and $\left(x_{n}\right)_{n \in \mathbb{N}}$ is bounded. Moreover

$$
\begin{aligned}
\left\|x_{n+1}-x_{n}\right\|^{2} & =\left\|x_{n+1}-x_{1}+x_{1}-x_{n}\right\|^{2} \\
& =\left\|x_{n+1}-x_{1}\right\|^{2}+\left\|x_{n}-x_{1}\right\|^{2}+2\left\langle x_{n+1}-x_{1}, x_{1}-x_{n}\right\rangle \\
& =\left\|x_{n+1}-x_{1}\right\|^{2}+\left\|x_{n}-x_{1}\right\|^{2}+2\left\langle x_{n+1}-x_{n}, x_{1}-x_{n}\right\rangle-2\left\|x_{n}-x_{1}\right\|^{2} \\
& \leq\left\|x_{n+1}-x_{1}\right\|^{2}-\left\|x_{n}-x_{1}\right\|^{2} \text { by }(3.5)
\end{aligned}
$$

and consequently $\lim _{n \rightarrow+\infty}\left\|x_{n+1}-x_{n}\right\|=0$.

Step 4. $\lim _{n \rightarrow+\infty}\left\|x_{n}-y_{n}\right\|=0$ and $\lim _{n \rightarrow+\infty}\left\|x_{n}-S_{k} z_{n}\right\|=0$.

By $x_{n+1} \in C_{n+1}$, it follows

$$
\begin{gathered}
\left\|y_{n}-x_{n+1}\right\| \leq\left\|x_{n}-x_{n+1}\right\| \\
\left\|y_{n}-x_{n}\right\| \leq\left\|y_{n}-x_{n+1}\right\|+\left\|x_{n+1}-x_{n}\right\| \leq 2\left\|x_{n+1}-x_{n}\right\| \longrightarrow 0
\end{gathered}
$$

Moreover

$$
\left\|y_{n}-x_{n}\right\|=\left(1-\alpha_{n}\right)\left\|x_{n}-S_{k} z_{n}\right\|
$$

and by boundedness of $\left(\alpha_{n}\right)_{n \in \mathbb{N}}$, it follows that $\lim _{n \rightarrow+\infty}\left\|x_{n}-S_{k} z_{n}\right\|=0$. 
Step 5. $\lim _{n \rightarrow+\infty}\left\|B u_{n}-B w\right\|=0$, for each $w \in F$.

For $w \in F$, we have

$$
\begin{aligned}
\left\|y_{n}-w\right\|^{2} & \leq \alpha_{n}\left\|x_{n}-w\right\|^{2}+\left(1-\alpha_{n}\right)\left\|S_{k} z_{n}-w\right\|^{2} \\
& \leq \alpha_{n}\left\|x_{n}-w\right\|^{2}+\left(1-\alpha_{n}\right)\left\|z_{n}-w\right\|^{2} \\
& \leq \alpha_{n}\left\|x_{n}-w\right\|^{2}+\left(1-\alpha_{n}\right)\left\|V_{n}\left(I-\lambda_{n} B\right) u_{n}-V_{n}\left(I-\lambda_{n} B\right) w\right\|^{2} \\
& \leq \alpha_{n}\left\|x_{n}-w\right\|^{2}+\left(1-\alpha_{n}\right)\left\|\left(I-\lambda_{n} B\right) u_{n}-\left(I-\lambda_{n} B\right) w\right\|^{2} \\
& =\alpha_{n}\left\|x_{n}-w\right\|^{2}+\left(1-\alpha_{n}\right)\left(\left\|u_{n}-w\right\|^{2}+\lambda_{n}^{2}\left\|B u_{n}-B w\right\|^{2}-2 \lambda_{n}\left\langle B u_{n}-B w, u_{n}-w\right\rangle\right) \\
& \leq \alpha_{n}\left\|x_{n}-w\right\|^{2}+\left(1-\alpha_{n}\right)\left(\left\|u_{n}-w\right\|^{2}-\lambda_{n}\left(2 \beta-\lambda_{n}\right)\left\|B u_{n}-B w\right\|^{2}\right) \\
& \leq\left\|x_{n}-w\right\|^{2}+\left(1-\alpha_{n}\right) \lambda_{n}\left(\lambda_{n}-2 \beta\right)\left\|B u_{n}-B w\right\|^{2} .
\end{aligned}
$$

\section{Consequently}

$$
\begin{aligned}
\left(1-\alpha_{n}\right) \lambda_{n}\left(2 \beta-\lambda_{n}\right)\left\|B u_{n}-B w\right\|^{2} & \leq\left\|x_{n}-w\right\|^{2}-\left\|y_{n}-w\right\|^{2} \\
& =\left(\left\|x_{n}-w\right\|-\left\|y_{n}-w\right\|\right)\left(\left\|x_{n}-w\right\|+\left\|y_{n}-w\right\|\right) \\
& \leq\left(\left\|x_{n}-y_{n}\right\|\right)\left(\left\|x_{n}-w\right\|+\left\|y_{n}-w\right\|\right),
\end{aligned}
$$

and by Step 4 , the assumptions on $\left(\alpha_{n}\right)_{n \in \mathbb{N}}$ and $\left(\lambda_{n}\right)_{n \in \mathbb{N}}$, we obtain the claim of Step 5 .

Step 6. $\lim _{n \rightarrow+\infty}\left\|u_{n}-z_{n}\right\|=0$.

Since $V_{n}$ is firmly nonexpansive, for any $w \in F$, we have

$$
\begin{aligned}
& \left\|z_{n}-w\right\|^{2} \leq\left\langle\left(I-\lambda_{n} B\right) u_{n}-\left(I-\lambda_{n} B\right) w, z_{n}-w\right\rangle \\
& =\frac{1}{4}\left\{\left\|\left(I-\lambda_{n} B\right) u_{n}-\left(I-\lambda_{n} B\right) w+\left(z_{n}-w\right)\right\|^{2}\right. \\
& \left.-\left\|\left(I-\lambda_{n} B\right) u_{n}-\left(I-\lambda_{n} B\right) w-\left(z_{n}-w\right)\right\|^{2}\right\} \\
& \leq \frac{1}{4}\left\{\left\|u_{n}-w\right\|^{2}-\lambda_{n}\left(2 \beta-\lambda_{n}\right)\left\|B u_{n}-B w\right\|^{2}+\left\|z_{n}-w\right\|^{2}\right. \\
& \left.-\left\|u_{n}-z_{n}-\lambda_{n}\left(B u_{n}-B w\right)\right\|^{2}\right\} \\
& \leq \frac{1}{4}\left\{\left\|u_{n}-w\right\|^{2}+\left\|z_{n}-w\right\|^{2}-\left\|u_{n}-z_{n}-\lambda_{n}\left(B u_{n}-B w\right)\right\|^{2}\right\} \\
& =\frac{1}{4}\left\{\left\|u_{n}-w\right\|^{2}+\left\|z_{n}-w\right\|^{2}-\left\|u_{n}-z_{n}\right\|^{2}\right. \\
& \left.+2 \lambda_{n}\left\langle u_{n}-z_{n}, B u_{n}-B w\right\rangle-\lambda_{n}^{2}\left\|B u_{n}-B w\right\|^{2}\right\}
\end{aligned}
$$


which implies

$$
\begin{aligned}
3\left\|z_{n}-w\right\|^{2} & \leq\left\|u_{n}-w\right\|^{2}-\left\|u_{n}-z_{n}\right\|^{2}+2 \lambda_{n}\left\langle u_{n}-z_{n}, B u_{n}-B w\right\rangle \\
& \leq\left\|x_{n}-w\right\|^{2}-\left\|u_{n}-z_{n}\right\|^{2}+2 \lambda_{n}\left\|u_{n}-z_{n}\right\|\left\|B u_{n}-B w\right\| .
\end{aligned}
$$

\section{Consequently}

$$
\begin{aligned}
\left\|y_{n}-w\right\|^{2} & \leq \alpha_{n}\left\|x_{n}-w\right\|^{2}+\left(1-\alpha_{n}\right)\left\|z_{n}-w\right\|^{2} \\
& \leq\left\|x_{n}-w\right\|^{2}-\left(1-\alpha_{n}\right)\left\|u_{n}-z_{n}\right\|^{2}+2\left(1-\alpha_{n}\right) \lambda_{n}\left\|u_{n}-z_{n}\right\|\left\|B u_{n}-B w\right\|
\end{aligned}
$$

which implies

$$
\begin{aligned}
\left(1-\alpha_{n}\right)\left\|u_{n}-z_{n}\right\|^{2} \leq & \left\|x_{n}-w\right\|^{2}-\left\|y_{n}-w\right\|^{2}+2\left(1-\alpha_{n}\right) \lambda_{n}\left\|u_{n}-z_{n}\right\|\left\|B u_{n}-B w\right\| \\
\leq & \left(\left\|x_{n}-w\right\|-\left\|y_{n}-w\right\|\right)\left(\left\|x_{n}-w\right\|+\left\|y_{n}-w\right\|\right) \\
& +2\left(1-\alpha_{n}\right) \lambda_{n}\left\|u_{n}-z_{n}\right\|\left\|B u_{n}-B w\right\| \\
\leq & \left(\left\|x_{n}-y_{n}\right\|\right)\left(\left\|x_{n}-w\right\|+\left\|y_{n}-w\right\|\right)+2\left(1-\alpha_{n}\right) \lambda_{n}\left\|u_{n}-z_{n}\right\|\left\|B u_{n}-B w\right\| .
\end{aligned}
$$

By the assumptions on $\left(\alpha_{n}\right)_{n \in \mathbb{N}}$, Steps 4 and 6, and the boundedness of $\left(x_{n}\right)_{n \in \mathbb{N}} \quad\left(y_{n}\right)_{n \in \mathbb{N}}$ and $\left(u_{n}\right)_{n \in \mathbb{N}}$ the claim follows.

Step 7. $\lim _{n \rightarrow+\infty}\left\|x_{n}-u_{n}\right\|=0$ and $\lim _{n \rightarrow+\infty}\left\|x_{n}-S_{k} x_{n}\right\|=0$.

Since $T_{n}$ is firmly nonexpansive, for each $p \in \cap_{n} \operatorname{Fix}\left(T_{n}\left(I-r_{n}\right) A\right.$ ), we have

$$
\begin{aligned}
\left\|u_{n}-p\right\|^{2}= & \left\|T_{n}\left(I-r_{n} A\right) x_{n}-T_{n}\left(I-r_{n} A\right) p\right\|^{2} \\
\leq & \left\langle u_{n}-p,\left(I-r_{n} A\right) x_{n}-\left(I-r_{n} A\right) p\right\rangle \\
= & \frac{1}{2}\left(\left\|\left(I-r_{n} A\right) x_{n}-\left(I-r_{n} A\right) p\right\|^{2}+\left\|u_{n}-p\right\|^{2}\right. \\
& \left.\quad-\left\|\left(I-r_{n} A\right) x_{n}-\left(I-r_{n} A\right) p-\left(u_{n}-p\right)\right\|^{2}\right) \\
= & \frac{1}{2}\left(\left\|x_{n}-p\right\|^{2}-r_{n}\left(2 \alpha-r_{n}\right)\left\|A x_{n}-A p\right\|^{2}+\left\|u_{n}-p\right\|^{2}\right. \\
& \left.\quad-\left\|x_{n}-u_{n}-r_{n}\left(A x_{n}-A p\right)\right\|^{2}\right) \\
\leq & \frac{1}{2}\left(\left\|x_{n}-p\right\|^{2}+\left\|u_{n}-p\right\|^{2}-\left\|x_{n}-u_{n}\right\|^{2}\right. \\
& \left.\quad-r_{n}^{2}\left\|A x_{n}-A p\right\|^{2}+2 r_{n}\left\langle x_{n}-u_{n}, A x_{n}-A p\right\rangle\right),
\end{aligned}
$$


and consequently

$$
\left\|u_{n}-p\right\|^{2} \leq\left(\left\|x_{n}-p\right\|^{2}-\left\|x_{n}-u_{n}\right\|^{2}+2 r_{n}\left\|x_{n}-u_{n}\right\|\left\|A x_{n}-A p\right\|\right)
$$

Then, for each $w \in F$, we have

$$
\begin{aligned}
\left\|y_{n}-w\right\|^{2} \leq & \alpha_{n}\left\|x_{n}-w\right\|^{2}+\left(1-\alpha_{n}\right)\left\|u_{n}-w\right\|^{2} \\
\leq & \left\|x_{n}-w\right\|^{2}-\left(1-\alpha_{n}\right)\left\|x_{n}-u_{n}\right\|^{2} \\
& \quad+2\left(1-\alpha_{n}\right) r_{n}\left\|x_{n}-u_{n}\right\|\left\|A x_{n}-A w\right\| \text { by (3.17), }
\end{aligned}
$$

consequently

$$
\begin{aligned}
\left(1-\alpha_{n}\right)\left\|x_{n}-u_{n}\right\|^{2} & \leq\left\|x_{n}-w\right\|^{2}-\left\|y_{n}-w\right\|^{2}+2\left(1-\alpha_{n}\right) r_{n}\left\|x_{n}-u_{n}\right\|\left\|A x_{n}-A w\right\| \\
& \leq\left\|x_{n}-y_{n}\right\|\left(\left\|x_{n}-w\right\|+\left\|y_{n}-w\right\|\right)+2\left(1-\alpha_{n}\right) r_{n}\left\|x_{n}-u_{n}\right\|\left\|A x_{n}-A w\right\|
\end{aligned}
$$

and by the assumptions on $\left(\alpha_{n}\right)_{n \in \mathbb{N}}$, Step 4 and the boundedness of $\left(x_{n}\right)_{n \in \mathbb{N}}$ and $\left(y_{n}\right)_{n \in \mathbb{N}}$ it follows that $\left\|x_{n}-u_{n}\right\| \rightarrow 0$ as $n \rightarrow+\infty$. By Step 6 we note that also $\left\|x_{n}-z_{n}\right\| \rightarrow 0$.

Finally

$$
\begin{aligned}
\left\|x_{n}-S_{k} x_{n}\right\| & \leq\left\|x_{n}-S_{k} z_{n}\right\|+\left\|S_{k} z_{n}-S_{k} x_{n}\right\| \\
& \leq\left\|x_{n}-S_{k} z_{n}\right\|+\left\|z_{n}-x_{n}\right\| \\
& \leq\left\|x_{n}-S_{k} z_{n}\right\|+\left\|z_{n}-u_{n}\right\|+\left\|u_{n}-x_{n}\right\|,
\end{aligned}
$$

and by previous steps, it follows that $\left\|x_{n}-S_{k} x_{n}\right\| \rightarrow 0$ as $n \rightarrow+\infty$.

Step 8. The set of weak cluster points of $\left(x_{n}\right)_{n \in \mathbb{N}}$ is contained in $F$.

We will use three times the Opial's Lemma 2.1.

Let $p$ be a weak cluster point of $\left(x_{n}\right)_{n \in \mathbb{N}}$ and let $\left(x_{n_{j}}\right)_{j \in \mathbb{N}}$ be a subsequence of $\left(x_{n}\right)_{n \in \mathbb{N}}$ such that $x_{n_{j}} \rightarrow p$.

We prove that $p \in \operatorname{Fix}(S)=\operatorname{Fix}\left(S_{k}\right)$. We suppose for absurd that $p \neq S_{k} p$. By Opial's Lemma 2.1 and $\left\|x_{n}-S_{k} x_{n}\right\| \rightarrow 0$ as $n \rightarrow \infty$, we obtain

$$
\begin{gathered}
\liminf _{j \rightarrow+\infty}\left\|x_{n_{j}}-p\right\|<\liminf _{j \rightarrow+\infty}\left\|x_{n_{j}}-S_{k} p\right\| \\
=\liminf _{j \rightarrow+\infty}\left\|x_{n_{j}}-S_{k} x_{n_{j}}-S_{k} x_{n_{j}}-S_{k} p\right\| \leq \liminf _{j \rightarrow+\infty}\left[\left\|x_{n_{j}}-S_{k} x_{n_{j}}\right\|+\left\|S_{k} x_{n_{j}}-S_{k} p\right\|\right] \\
=\liminf _{j \rightarrow+\infty}\left\|x_{n_{j}}-p\right\|
\end{gathered}
$$

which is a contradiction. 
Since $\operatorname{Fix}(R)=\cap_{n} \operatorname{Fix}\left(T_{n}\left(I-r_{n} A\right)\right)$ it is enough to prove that $p \in \operatorname{Fix}(R)$. Now if $p \neq R p$ we note that

$$
\begin{aligned}
\liminf _{j \rightarrow+\infty}\left\|x_{n_{j}}-p\right\| & <\liminf _{j \rightarrow+\infty}\left\|x_{n_{j}}-R p\right\| \\
\leq & \liminf _{j \rightarrow+\infty}\left[\left\|x_{n_{j}}-T_{n_{j}}\left(I-r_{n_{j}} A\right) x_{n_{j}}\right\|\right. \\
& \left.+\left\|T_{n_{j}}\left(I-r_{n_{j}} A\right) x_{n_{j}}-T_{n_{j}}\left(I-r_{n_{j}} A\right) p\right\|+\left\|T_{n_{j}}\left(I-r_{n_{j}} A\right) p-R p\right\|\right] \\
& \leq \liminf _{j \rightarrow+\infty}\left[\left\|x_{n_{j}}-u_{n_{j}}\right\|+\left\|x_{n_{j}}-p\right\|+\left\|T_{n_{j}}\left(I-r_{n_{j}} A\right) p-R p\right\|\right] \\
& =\liminf _{j \rightarrow+\infty}\left\|x_{n_{j}}-p\right\| .
\end{aligned}
$$

This leads to a contraddiction again. By the hypotheses and Step 7 the claim follows. By the same idea and using Step 6, we prove that $p \in \operatorname{Fix}(W)=\cap_{n} \operatorname{Fix}\left(V_{n}\left(I-\lambda_{n} B\right)\right)$.

Step 9. $x_{n} \rightarrow x^{*}=P_{F} x_{1}$.

Since $x^{*}=P_{F} x_{1} \in C_{n}$ and $x_{n}=P_{C_{n}} x_{1}$, we have

$$
\left\|x_{1}-x_{n}\right\| \leq\left\|x_{1}-x^{*}\right\|
$$

Let $\left(x_{n_{j}}\right)_{j \in \mathbb{N}}$ be a subsequence of $\left(x_{n}\right)_{n \in \mathbb{N}}$ such that $x_{n_{j}} \rightarrow p$. By Step $8, p \in F$. Thus

$$
\begin{aligned}
\left\|x_{1}-x^{*}\right\| & \leq\left\|x_{1}-p\right\| \leq \liminf _{j \rightarrow+\infty}\left\|x_{1}-x_{n_{j}}\right\| \\
& \leq \limsup _{j \rightarrow+\infty}\left\|x_{1}-x_{n_{j}}\right\| \leq\left\|x_{1}-x^{*}\right\| .
\end{aligned}
$$

Therefore we have

$$
\left\|x_{1}-x^{*}\right\|=\left\|x_{1}-p\right\|=\lim _{j \rightarrow+\infty}\left\|x_{1}-x_{n_{j}}\right\| .
$$

Since $H$ has the Kadec-Klee property, then $x_{n_{j}} \rightarrow p$ as $j \rightarrow+\infty$.

Moreover, by $\left\|x_{1}-x^{*}\right\|=\left\|x_{1}-p\right\|$ and by the uniqueness of the projection $P_{F} x_{1}$, it follows that $p=x^{*}=P_{F} x_{1}$.

Thence every subsequence $\left(x_{n_{j}}\right)_{j \in \mathbb{N}}$ converges to $x^{*}$ as $j \rightarrow+\infty$ and consequently $x_{n} \rightarrow x^{*}$, as $n \rightarrow+\infty$.

Remark 3.2. Let us observe that one can choose $\left(T_{n}\right)_{n \in \mathbb{N}}$ and $\left(V_{n}\right)_{n \in \mathbb{N}}$ as sequences of $\gamma_{n^{-}}$ inverse strongly monotone operators and $\eta_{n}$-inverse strongly monotone operators provided $\gamma_{n} \geq 1, \eta_{n} \geq 1$ for all $n \in \mathbb{N}$. 
The hypotheses (ii) and (iii) in the main Theorem 3.1 seem very strong but, in the sequel, we furnish two cases in which (ii) and (iii) are satisfied.

Let us remember that the metric projection on a convex closed set $P_{C}$ is a firmly nonexpansive mapping (see [19]) so we claim that have the following proposition.

Proposition 3.3. If $\left(r_{n}\right)_{n \in \mathbb{N}} \subset(0, \infty)$ is such that $\lim _{n} r_{n}=r>0$ and $A$ an $\alpha$-inverse strongly monotone, then $P_{C}\left(I-r_{n} A\right)$ realizes conditions (ii) and (iii) with $R=P_{C}(I-r A)$.

Proof. To prove (ii) we note that for each $x \in C$,

$$
\left\|P_{C}\left(I-r_{n} A\right) x-P_{C}(I-r A) x\right\| \leq\left\|\left(I-r_{n} A\right) x-(I-r A) x\right\| \leq\left|r_{n}-r\right|\|A x\| .
$$

Moreover, (iii) follows directly by (2.2).

Now we consider the mixed equilibrium problem

$$
\text { Find } x \in C: f(x, y)+h(x, y)+\langle A x, y-x\rangle \geq 0, \quad \forall y \in C \text {. }
$$

In the sequel we will indicate with $\operatorname{MEP}(f, h, A)$ the set of solution of our mixed equilibrium problem. If $A=0$ we denote $\operatorname{MEP}(f, h, 0)$ with $M E P(f, h)$.

We notice that for $h=0$ and $A=0$ the problem is the well-known equilibrium problem [23-25]. If $h=0$ and $A$ is an $\alpha$-inverse strongly monotone operator we have the equilibrium problems studied firstly in [26] and then in [18, 22, 27]. If $h(x, y)=\varphi(y)-\varphi(x)$ and $A=0$ we refound the mixed equilibrium problem studied in $[16,28,29]$.

Definition 3.4. A bi-function $g: C \times C \rightarrow \mathbb{R}$ is monotone if $g(x, y)+g(y, x) \leq 0$ for all $x, y \in C$.

A function $G: C \rightarrow \mathbb{R}$ is upper hemicontinuous if

$$
\limsup _{t \rightarrow 0} G(t x+(1-t) y) \leq G(y)
$$

Next lemma examines the case in which $A=0$.

Lemma 3.5. Let $C$ be a convex closed subset of a Hilbert space $H$.

Let $f: C \times C \rightarrow \mathbb{R}$ be a bi-function such that

(f1) $f(x, x)=0$ for all $x \in C$;

(f2) $f$ is monotone and upper hemicontinuous in the first variable;

(f3) $f$ is lower semicontinuous and convex in the second variable.

Let $h: C \times C \rightarrow \mathbb{R}$ be a bi-function such that

(h1) $h(x, x)=0$ for all $x \in C$;

(h2) $h$ is monotone and weakly upper semicontinuous in the first variable;

(h3) $h$ is convex in the second variable. 
Fixed Point Theory and Applications

Moreover let us suppose that

(H) for fixed $r>0$ and $x \in C$, there exists a bounded set $K \subset C$ and $a \in K$ such that for all $z \in C \backslash K,-f(a, z)+h(z, a)+(1 / r)\langle a-z, z-x\rangle<0$,

for $r>0$ and $x \in H$ let $T_{r}: H \rightarrow C$ be a mapping defined by

$$
T_{r} x=\left\{z \in C: f(z, y)+h(z, y)+\frac{1}{r}\langle y-z, z-x\rangle \geq 0, \quad \forall y \in C\right\}
$$

called resolvent of $f$ and $h$.

Then

(1) $T_{r} x \neq \emptyset$;

(2) $T_{r} x$ is a single value;

(3) $T_{r}$ is firmly nonexpansive;

(4) $\operatorname{MEP}(f, h)=\operatorname{Fix}\left(T_{r}\right)$ and it is closed and convex.

Proof. Let $x_{0} \in H$. For any $y \in C$ define

$$
G_{r, x_{0}} y=\left\{z \in C:-f(y, z)+h(z, y)+\frac{1}{r}\langle y-z, z-x\rangle \geq 0\right\} .
$$

We will prove that, by KKM's lemma, $\cap_{y \in C} G_{r, x_{0}} y$ is nonempty.

First of all we claim that $G_{r, x_{0}}$ is a KKM's map. In fact if there exists $\left\{y_{1}, \ldots, y_{N}\right\} \subset C$ such that $\bar{y}=\sum_{i} \alpha_{i} y_{i}$ (with $\sum_{i} \alpha_{i}=1$ ) does not appartiene to $G_{r, x_{0}} y_{i}$ for any $i=1, \ldots, N$ then

$$
-f\left(y_{i}, \bar{y}\right)+h\left(\bar{y}, y_{i}\right)+\frac{1}{r}\left\langle y_{i}-\bar{y}, \bar{y}-x_{0}\right\rangle<0, \quad \forall i
$$

By the convexity of $f$ and $h$ and the monotonicity of $f$, we obtain that

$$
\begin{aligned}
0 & =f(\bar{y}, \bar{y})+h(\bar{y}, \bar{y})+\frac{1}{r}\left\langle\bar{y}-\bar{y}, \bar{y}-x_{0}\right\rangle \\
& \leq \sum_{i} \alpha_{i} f\left(\bar{y}, y_{i}\right)+\sum_{i} \alpha_{i} h\left(\bar{y}, y_{i}\right)+\frac{1}{r} \sum_{i} \alpha_{i}\left\langle y_{i}-\bar{y}, \bar{y}-x_{0}\right\rangle \\
& \leq-\sum_{i} \alpha_{i} f\left(y_{i}, \bar{y}\right)+\sum_{i} \alpha_{i} h\left(\bar{y}, y_{i}\right)+\frac{1}{r} \sum_{i} \alpha_{i}\left\langle y_{i}-\bar{y}, \bar{y}-x_{0}\right\rangle \\
& =\sum_{i} \alpha_{i}\left[-f\left(y_{i}, \bar{y}\right)+h\left(\bar{y}, y_{i}\right)+\frac{1}{r}\left\langle y_{i}-\bar{y}, \bar{y}-x_{0}\right\rangle\right]<0,
\end{aligned}
$$

that is absurd. 
Now we prove that ${\overline{G_{r, x_{0}}}}^{w}=G_{r, x_{0}}$. We recall that, by the weak lower semicontinuity of $\|\cdot\|^{2}$, the relation

$$
\limsup _{m}\left\langle y-z_{m}, z_{m}-x_{0}\right\rangle \leq\left\langle y-z, z-x_{0}\right\rangle
$$

holds. Let $z \in{\overline{G_{r, x_{0}} y}}^{w}$ and let $\left(z_{m}\right)_{m}$ be a sequence in $G_{r, x_{0}} y$ such that $z_{m}-z$.

We want to prove that

$$
-f(y, z)+h(z, y)+\frac{1}{r}\left\langle y-z, z-x_{0}\right\rangle \geq 0
$$

Since $f$ is lower semicontinuous and convex in the second variable and $h$ is weakly upper semicontinuous in the first variable, then

$$
\begin{aligned}
0 & \leq \limsup _{m}\left[-f\left(y, z_{m}\right)+h\left(z_{m}, y\right)+\frac{1}{r}\left\langle y-z, z-x_{0}\right\rangle\right] \\
& \leq \limsup _{m}\left(-f\left(y, z_{m}\right)\right)+\underset{m}{\lim \sup } h\left(z_{m}, y\right)+\frac{1}{r} \limsup _{m}\left\langle y-z, z-x_{0}\right\rangle \\
& \leq-\liminf _{m} f\left(y, z_{m}\right)+\limsup _{m} h\left(z_{m}, y\right)+\frac{1}{r} \limsup _{m}\left\langle y-z, z-x_{0}\right\rangle \\
& \leq-f(y, z)+h(z, y)+\frac{1}{r}\left\langle y-z, z-x_{0}\right\rangle .
\end{aligned}
$$

Now we observe that ${\overline{G_{r, x_{0}} y}}^{w}=G_{r, x_{0}} y$ is weakly compact for at least a point $y \in C$. In fact by hypothesis $(\mathrm{H})$ there exist a bounded $K \subset C$ and $a \in K$, such that for all $z \in C \backslash K$ it results $z \notin G_{r, x_{0}} a$. Then $G_{r, x_{0}}$ a $\subset K$, that is, it is bounded. It follows that $G_{r, x_{0}} a$ is weakly compact. Then by KKM's lemma $\cap_{y \in C} G_{r, x_{0}} y$ is nonempty. However if $z \in \cap_{y \in C} G_{r, x_{0}}$ then

$$
-f(y, z)+h(z, y)+\frac{1}{r}\left\langle y-z, z-x_{0}\right\rangle \geq 0, \quad \forall y \in C
$$

As in [24, Lemma 3], since $f$ is upper hemicontinuous and convex in the first variable and monotone, we obtain that (3.36) is equivalent to claim that $z$ is such that

$$
f(z, y)+h(z, y)+\frac{1}{r}\left\langle y-z, z-x_{0}\right\rangle \geq 0, \quad \forall y \in C,
$$

that is, $z \in T_{r}\left(x_{0}\right)$. This prove (1). To prove (2) and (3) we consider $z_{1} \in T_{r} x_{1}$ and $z_{2} \in T_{r} x_{2}$. They satisfy the relations

$$
\begin{aligned}
& f\left(z_{1}, z_{2}\right)+h\left(z_{1}, z_{2}\right)+\frac{1}{r}\left\langle z_{2}-z_{1}, z_{1}-x_{1}\right\rangle \geq 0, \\
& f\left(z_{2}, z_{1}\right)+h\left(z_{2}, z_{1}\right)+\frac{1}{r}\left\langle z_{1}-z_{2}, z_{2}-x_{2}\right\rangle \geq 0 .
\end{aligned}
$$


By the monotonicity of $f$ and $h$, summing up both the terms,

$$
\begin{aligned}
0 & \leq \frac{1}{r}\left[\left\langle z_{2}-z_{1}, z_{1}-x_{1}\right\rangle-\left\langle z_{2}-z_{1}, z_{2}-x_{2}\right\rangle\right] \\
& =\frac{1}{r}\left[\left\langle z_{2}-z_{1}, z_{1}-x_{1}-z_{2}+x_{2}\right\rangle\right] \\
& =\frac{1}{r}\left[-\left\|z_{2}-z_{1}\right\|^{2}+\left\langle z_{2}-z_{1}, x_{2}-x_{1}\right\rangle\right]
\end{aligned}
$$

so we conclude

$$
\left\|z_{2}-z_{1}\right\|^{2} \leq\left\langle z_{2}-z_{1}, x_{2}-x_{1}\right\rangle
$$

that means simultaneously that $z_{1}=z_{2}$ if $x_{1}=x_{2}$ and $T_{r}$ is firmly nonexpansive.

To prove (4), it is enough to follow (iii) and (iv) in [25, Lemma 2.12].

Remark 3.6. We note that if $h=0$, our lemma reduces to [25, Lemma 2.12]. The coercivity condition $(\mathrm{H})$ is fulfilled.

Moreover our lemma is more general than [16, Lemma 2.2]. In fact

(i) our hypotheses on $f$ are weaker ( $f$ weak upper semicontinuous implies $f$ upper hemicontinuous);

(ii) if $\varphi$ satisfies the condition in Lemma 2.2 , choosing $h(x, y)=\varphi(y)-\varphi(x)$ one has that $h$ is concave and upper semicontinuous in the first variable and convex and lower semicontinous in the second variable;

(iii) the coercivity condition $(\mathrm{H})$ by the equivalence of (3.36) and (3.37) is the same.

Lemma 3.7. Let us suppose that (f1)-(f3), (h1)-(h3) and (H) hold. Let $x, y \in H, r_{1}, r_{2}>0$. Then

$$
\left\|T_{r_{2}} y-T_{r_{1}} x\right\| \leq\|y-x\|+\left|\frac{r_{2}-r_{1}}{r_{2}}\right|\left\|T_{r_{2}} y-y\right\| .
$$

Proof. By Lemma 3.5, defining $u_{1}=T_{r_{1}} x$ and $u_{2}:=T_{r_{2}} y$, we know that

$$
\begin{array}{ll}
f\left(u_{2}, z\right)+h\left(u_{2}, z\right)+\frac{1}{r_{2}}\left\langle z-u_{2}, u_{2}-y\right\rangle \geq 0, & \forall z \in C, \\
f\left(u_{1}, z\right)+h\left(u_{1}, z\right)+\frac{1}{r_{1}}\left\langle z-u_{1}, u_{1}-x\right\rangle \geq 0, & \forall z \in C .
\end{array}
$$

In particular,

$$
\begin{aligned}
& f\left(u_{2}, u_{1}\right)+h\left(u_{2}, u_{1}\right)+\frac{1}{r_{2}}\left\langle u_{1}-u_{2}, u_{2}-y\right\rangle \geq 0 \\
& f\left(u_{1}, u_{2}\right)+h\left(u_{1}, u_{2}\right)+\frac{1}{r_{1}}\left\langle u_{2}-u_{1}, u_{1}-x\right\rangle \geq 0
\end{aligned}
$$


Hence, summing up this two inequalities and using the monotonicity of $f$ and $h$,

$$
\left\langle u_{2}-u_{1}, \frac{u_{1}-x}{r_{1}}-\frac{u_{2}-y}{r_{2}}\right\rangle \geq 0
$$

We derive from (3.44) that

$$
\left\langle u_{2}-u_{1}, u_{1}-u_{2}-x+u_{2}-\frac{r_{1}}{r_{2}}\left(u_{2}-y\right)\right\rangle \geq 0
$$

and so

$$
-\left\|u_{2}-u_{1}\right\|^{2}+\left\langle u_{2}-u_{1},\left(u_{2}-y\right)\left(1-\frac{r_{1}}{r_{2}}\right)+(y-x)\right\rangle \geq 0
$$

Then,

$$
\left\|u_{2}-u_{1}\right\|^{2} \leq\left\|u_{2}-u_{1}\right\|\left(\|y-x\|+\left|1-\frac{r_{1}}{r_{2}}\right|\left\|u_{2}-y\right\|\right)
$$

and thus the claim holds.

Proposition 3.8. Let us suppose that $f$ and $h$ are two bi-functions satisfying the hypotheses of Lemma 3.5. Let $T_{r}$ be the resolvent of $f$ and $h$. Let $A$ be an $\alpha$-inverse strongly monotone operator. Let us suppose that $\left(r_{n}\right)_{n \in \mathbb{N}} \subset(0, \infty)$ is such that $\lim _{n} r_{n}=r>0$. Then $T_{r_{n}}\left(I-r_{n} A\right)$ realize (ii) and (iii) in Theorem 3.1.

Proof. Let $x$ be in a bounded closed convex subset $K$ of $C$. To prove (i) it is enough to observe that by Lemma 3.7

$$
\left\|T_{r_{n}}\left(I-r_{n} A\right) x-T_{r}(I-r A) x\right\| \leq\left|r_{n}-r\right|\|A x\|+\frac{\left|r_{n}-r\right|}{r}\left\|T_{r}(I-r A) x-(I-r A) x\right\| .
$$

When $n \rightarrow \infty$, by boundedness of the terms that do not depend on $n$, we obtain (ii).

To prove (iii) let $W=T_{r}(I-r A)$ the pointwise limit of $T_{r_{n}}\left(I-r_{n} A\right)$. It is necessary to prove only that $\operatorname{Fix}(W) \subset \cap_{n} \operatorname{Fix}\left(T_{r_{n}}\left(I-r_{n} A\right)\right)$. Let $x \in \operatorname{Fix}(W)$. We want to prove that $x \in \operatorname{MEP}(f, h, A)$. Let $w_{n}=T_{r_{n}}\left(I-r_{n} A\right) x$. Thus, by definition of $T_{r_{n}}, w_{n}$ is the unique point such that

$$
f\left(w_{n}, y\right)+h\left(w_{n}, y\right)+\frac{1}{r_{n}}\left\langle y-w_{n}, w_{n}-\left(I-r_{n} A\right) x\right\rangle \geq 0, \quad \forall y
$$

By monotonicity of $f$ and $h$ this implies

$$
h\left(w_{n}, y\right)+\frac{1}{r_{n}}\left\langle y-w_{n}, w_{n}-\left(I-r_{n} A\right) x\right\rangle \geq f\left(y, w_{n}\right) .
$$


Passing to the limit on $n$, by (f3) and (h2) we obtain

$$
h(x, y)+\langle y-x, A x\rangle \geq f(y, x), \quad \forall y .
$$

Let now $u=t y+(1-t) x$ with $t \in[0,1]$. Then by the convexity of $f$ and $h$

$$
\begin{aligned}
0=f(u, u)+h(u, u) & \leq t[f(u, y)+h(u, y)]+(1-t)[f(u, x)+h(u, x)] \\
& \leq t[f(u, y)+h(u, y)]+\langle u-x, A x\rangle \\
& =t[f(u, y)+h(u, y)+\langle y-x, A x\rangle] .
\end{aligned}
$$

Passing $t \rightarrow 0^{+}$we obtain by (f1) and (h1)

$$
f(x, y)+h(x, y)+\langle A x, y-x\rangle \geq 0 \text {. }
$$

That is, $x \in \operatorname{MEP}(f, h, A)$. At this point we observe that from the definitions of $\operatorname{MEP}(f, h, A)$ and $T_{r_{n}}$, one has $\operatorname{MEP}(f, h, A)=\operatorname{Fix}\left(T_{r_{n}}\left(I-r_{n} A\right)\right)$.

By Propositions 3.3 and 3.8 we can exhibit iterative methods to approximate fixed points of the $k$-strict pseudo contraction that are also

(1) solution of a system of two variational inequalities $\operatorname{VI}(\mathrm{C}, \mathrm{A})$ and $\operatorname{VI}(\mathrm{C}, \mathrm{B})\left(V_{n}=T_{n}=\right.$ $\left.P_{C}\right)$;

(2) solution of a system of two mixed equilibrium problems $\left(T_{n}=T_{r_{n}}\right.$ and $\left.V_{n}=T_{\lambda_{n}}\right)$;

(3) solution of a mixed equilibrium problem and a variational inequality $\left(T_{n}=T_{r_{n}}\right.$ and $\left.V_{n}=P_{C}\right)$.

However when the properties of the mapping $T_{n}$ and $V_{n}$ are well known, one can prove convergence theorems like Theorem 3.1 without use of Opial's lemma.

In next theorem our purpose is to prove a strong convergence theorem to approximate a fixed point of $S$ that is also a solution of a mixed equilibrium problem and a solution of a variational inequality $V I(C, B)$. One can note that we relax the hypotheses on the convergence of the sequences $\left(r_{n}\right)_{n \in \mathbb{N}}$ and $\left(\lambda_{n}\right)_{n \in \mathbb{N}}$.

Theorem 3.9. Let $C$ be a closed convex subset of a real Hilbert space $H$, let $f, h: C \times C \rightarrow \mathbb{R}$ be two bi-functions satisfying (f1)-(f3),(h1)-(h3), and (H). Let $S: C \rightarrow C$ be a $k$-strict pseudocontraction.

Let $A$ be an $\alpha$-inverse strongly monotone mapping of $C$ into $H$ and let $B$ be a $\beta$-inverse strongly monotone mapping of $C$ into $H$.

Let us suppose that $F=\operatorname{Fix}(S) \cap M E P(f, h, A) \cap V I(C, B) \neq \emptyset$. 
Set $S_{k}=k I+(1-k) S$, one defines the sequence $\left(x_{n}\right)_{n \in \mathbb{N}}$ as follows:

$$
\begin{gathered}
x_{1} \in C, \\
C_{1}=C, \\
f\left(u_{n}, y\right)+h\left(u_{n}, y\right)+\frac{1}{r_{n}}\left\langle y-u_{n}, u_{n}-x_{n}\right\rangle+\left\langle A x_{n}, y-u_{n}\right\rangle \geq 0, \\
z_{n}=P_{C}\left(I-\lambda_{n} B\right) u_{n}, \\
y_{n}=\alpha_{n} x_{n}+\left(1-\alpha_{n}\right) S_{k} z_{n}, \\
C_{n+1}=\left\{w \in C_{n}:\left\|y_{n}-w\right\| \leq\left\|x_{n}-w\right\|\right\}, \\
x_{n+1}=P_{C_{n+1}} x_{1}, \quad \forall n \in N,
\end{gathered}
$$

where

(i) $\left(\alpha_{n}\right)_{n \in \mathbb{N}} \subset[0, a]$ with $a<1$;

(ii) $\left(\lambda_{n}\right)_{n \in \mathbb{N}} \subset[b, c] \subset(0,2 \beta)$;

(iii) $\left(r_{n}\right)_{n \in \mathbb{N}} \subset[d, e] \subset(0,2 \alpha)$.

Then $\left(x_{n}\right)_{n \in \mathbb{N}}$ strongly converges to $x^{*}=P_{F} x_{1}$.

Proof. First of all we observe that by Lemma 3.5 we have that $u_{n}=T_{r_{n}}\left(I-r_{n} A\right) x_{n}$. We can follow the proof of Theorem 3.1 from Steps 1-7. We prove only the following.

Step 10. The set of weak cluster points of $\left(x_{n}\right)_{n \in \mathbb{N}}$ is contained in $F$.

Let $p$ be a cluster point of $x_{n}$; we begin to prove that $p \in \operatorname{MEP}(f, h, A)$. We know that

$$
f\left(u_{n}, y\right)+h\left(u_{n}, y\right)+\left\langle A x_{n}, y-u_{n}\right\rangle+\frac{1}{r_{n}}\left\langle y-u_{n}, u_{n}-x_{n}\right\rangle \geq 0, \quad \forall y \in C,
$$

and by (f2)

$$
h\left(u_{n}, y\right)+\left\langle A x_{n}, y-u_{n}\right\rangle+\frac{1}{r_{n}}\left\langle y-u_{n}, u_{n}-x_{n}\right\rangle \geq f\left(y, u_{n}\right), \quad \forall y \in C .
$$

Let $\left(x_{n_{j}}\right)_{j \in \mathbb{N}}$ be a subsequence of $\left(x_{n}\right)_{n \in \mathbb{N}}$ weakly convergent to $p$, then by Step $7 u_{n_{j}} \rightarrow p$ as $j \rightarrow+\infty$. Let $\left.\left.\rho_{t}:=t y+(1-t) p, t \in\right] 0,1\right]$. Then by (3.56)

$$
\begin{aligned}
\left\langle\rho_{t}-u_{n_{j}}, A \rho_{t}\right\rangle= & \left\langle\rho_{t}-u_{n_{j}}, A \rho_{t}-A x_{n_{j}}\right\rangle+\left\langle A x_{n_{j}}, \rho_{t}-u_{n_{j}}\right\rangle \\
\geq & \left\langle\rho_{t}-u_{n_{j}}, A \rho_{t}-A x_{n_{j}}\right\rangle+f\left(y, u_{n_{j}}\right)-h\left(u_{n_{j}}, y\right)-\frac{1}{r_{n_{j}}}\left\langle y-u_{n_{j}}, u_{n_{j}}-x_{n_{j}}\right\rangle \\
= & \left\langle\rho_{t}-u_{n_{j}}, A \rho_{t}-A u_{n_{j}}\right\rangle+\left\langle\rho_{t}-u_{n_{j}}, A u_{n_{j}}-A x_{n_{j}}\right\rangle \\
& +f\left(y, u_{n_{j}}\right)-h\left(u_{n_{j}}, y\right)-\frac{1}{r_{n_{j}}}\left\langle y-u_{n_{j}}, u_{n_{j}}-x_{n_{j}}\right\rangle \\
\geq & \left\langle\rho_{t}-u_{n_{j}}, A u_{n_{j}}-A x_{n_{j}}\right\rangle+f\left(y, u_{n_{j}}\right)-h\left(u_{n_{j}}, y\right)-\frac{1}{r_{n_{j}}}\left\langle y-u_{n_{j}}, u_{n_{j}}-x_{n_{j}}\right\rangle .
\end{aligned}
$$


Since $A$ is Lipschitz continuous and $\left\|u_{n_{j}}-x_{n_{j}}\right\| \rightarrow 0$ as $j \rightarrow+\infty$, we have $\left\|A u_{n_{j}}-A x_{n_{j}}\right\| \rightarrow 0$ as $j \rightarrow+\infty$.

By condition $(f 3)$, for $x \in H$ fixed, the function $f(x, \cdot)$ is lower semicontinuos and convex, and thus weakly lower semicontinuous [30].

Since $\left\|x_{n}-u_{n}\right\| \rightarrow 0$, as $n \rightarrow \infty$ and by the assumption on $r_{n}$ we obtain $\left(u_{n_{j}}-x_{n_{j}}\right) / r_{n_{j}} \rightarrow$ 0 . Then we obtain by (h2)

$$
\left\langle\rho_{t}-p, A \rho_{t}\right\rangle \geq f(y, p)-h(p, y)
$$

Using (f1), (f3), (h1), (h3) we obtain

$$
\begin{aligned}
0 & =f\left(\rho_{t}, \rho_{t}\right)+h\left(\rho_{t}, \rho_{t}\right) \leq t f\left(\rho_{t}, y\right)+(1-t) f\left(\rho_{t}, p\right)+t h\left(\rho_{t}, y\right)+(1-t) h\left(\rho_{t}, p\right) \\
& \leq t f\left(\rho_{t}, y\right)+t h\left(\rho_{t}, y\right)+(1-t)\left(f\left(\rho_{t}, p\right)-h\left(p, \rho_{t}\right)\right) \\
& \leq t f\left(\rho_{t}, y\right)+t h\left(\rho_{t}, y\right)+(1-t)\left\langle\rho_{t}-p, A \rho_{t}\right\rangle \\
& =t\left(f\left(\rho_{t}, y\right)+h\left(\rho_{t}, y\right)+(1-t)\left\langle y-p, A \rho_{t}\right\rangle\right) .
\end{aligned}
$$

Consequently

$$
f\left(\rho_{t}, y\right)+h\left(\rho_{t}, y\right)+(1-t)\left\langle y-p, A \rho_{t}\right\rangle \geq 0
$$

by (f2) and (h2), as $t \rightarrow 0$, we obtain $p \in \operatorname{MEP}(f, h, A)$.

Now we prove that $p \in V I(C, B)$.

We define the maximal monotone operator

$$
T x= \begin{cases}B x+N_{C} x, & \text { if } x \in C, \\ \emptyset, & \text { se } x \notin C,\end{cases}
$$

where $N_{C} x$ is the normal cone to $C$ at $x$, that is,

$$
N_{C} x=\{w \in H:\langle x-u, w\rangle \geq 0, \forall u \in C\} .
$$

Since $z_{n} \in C$, by the definition of $N_{C}$ we have

$$
\left\langle x-z_{n}, y-B x\right\rangle \geq 0
$$

But $z_{n}=P_{C}\left(I-\lambda_{n} B\right) u_{n}$, then

$$
\left\langle x-z_{n}, z_{n}-\left(I-\lambda_{n} B\right) u_{n}\right\rangle \geq 0,
$$

and hence

$$
\left\langle x-z_{n}, \frac{z_{n}-u_{n}}{\lambda_{n}}+B u_{n}\right\rangle \geq 0 .
$$


By (3.63), (3.65), and by the $\beta$-inverse monotonicity of $B$, we obtain

$$
\begin{aligned}
\left\langle x-z_{n_{j}}, y\right\rangle \geq & \left\langle x-z_{n_{j}}, B x\right\rangle \\
\geq & \left\langle x-z_{n_{j}}, B x\right\rangle-\left\langle x-z_{n_{j}}, \frac{z_{n_{j}}-u_{n_{j}}}{\lambda_{n_{j}}}+B u_{n_{j}}\right\rangle \\
= & \left\langle x-z_{n_{j}}, B x-B z_{n_{j}}\right\rangle+\left\langle x-z_{n_{j}}, B z_{n_{j}}-B u_{n_{j}}\right\rangle \\
& -\left\langle x-z_{n_{j}}, \frac{z_{n_{j}}-u_{n_{j}}}{\lambda_{n_{j}}}\right\rangle .
\end{aligned}
$$

By $\left\|x_{n}-z_{n}\right\| \rightarrow 0$ as $n \rightarrow+\infty$ (immediately consequence of Steps 6 and 7), it follows that $z_{n_{j}} \rightarrow p$ as $j \rightarrow+\infty$. Then

$$
\langle x-p, y\rangle \geq 0
$$

moreover, since $T$ is a maximal operator, $0 \in T p$, that is, $p \in V I(C, B)$.

Finally, to prove that $p \in \operatorname{Fix}(S)=\operatorname{Fix}\left(S_{k}\right)$ we follow Step 8 as in Theorem 3.1.

Since also Step 9 can be followed as in Theorem 3.1, we obtain the claim.

\section{References}

[1] G. L. Acedo and H.-K. Xu, "Iterative methods for strict pseudo-contractions in Hilbert spaces," Nonlinear Analysis: Theory, Methods \& Applications, vol. 67, no. 7, pp. 2258-2271, 2007.

[2] F. E. Browder and W. V. Petryshyn, "Construction of fixed points of nonlinear mappings in Hilbert space," Journal of Mathematical Analysis and Applications, vol. 20, pp. 197-228, 1967.

[3] F. E. Browder, "Nonexpansive nonlinear operators in a Banach space," Proceedings of the National Academy of Sciences of the United States of America, vol. 54, pp. 1041-1044, 1965.

[4] K. Goebel and W. A. Kirk, "A fixed point theorem for asymptotically nonexpansive mappings," Proceedings of the American Mathematical Society, vol. 35, pp. 171-174, 1972.

[5] W. A. Kirk, "A fixed point theorem for mappings which do not increase distances," The American Mathematical Monthly, vol. 72, pp. 1004-1006, 1965.

[6] Q. Liu, "Convergence theorems of the sequence of iterates for asymptotically demicontractive and hemicontractive mappings," Nonlinear Analysis: Theory, Methods E Applications, vol. 26, no. 11, pp. 1835-1842, 1996.

[7] J. Schu, "Iterative construction of fixed points of asymptotically nonexpansive mappings," Journal of Mathematical Analysis and Applications, vol. 158, no. 2, pp. 407-413, 1991.

[8] H. K. Xu, "Inequalities in Banach spaces with applications," Nonlinear Analysis: Theory, Methods $\mathcal{E}$ Applications, vol. 16, no. 12, pp. 1127-1138, 1991.

[9] H. K. Xu, "Existence and convergence for fixed points of mappings of asymptotically nonexpansive type," Nonlinear Analysis: Theory, Methods E Applications, vol. 16, no. 12, pp. 1139-1146, 1991.

[10] L.-C. Ceng, S. Al-Homidan, Q. H. Ansari, and J.-C. Yao, "An iterative scheme for equilibrium problems and fixed point problems of strict pseudo-contraction mappings," Journal of Computational and Applied Mathematics, vol. 223, no. 2, pp. 967-974, 2009.

[11] G. Marino and H.-K. Xu, "Weak and strong convergence theorems for strict pseudo-contractions in Hilbert spaces," Journal of Mathematical Analysis and Applications, vol. 329, no. 1, pp. 336-346, 2007.

[12] G. Marino, V. Colao, X. Qin, and S. M. Kang, "Strong convergence of the modified Mann iterative method for strict pseudo-contractions," Computers and Mathematics with Applications, vol. 57, no. 3, pp. 455-465, 2009.

[13] H. Zhou, "Convergence theorems of fixed points for $\kappa$-strict pseudo-contractions in Hilbert spaces," Nonlinear Analysis: Theory, Methods \& Applications, vol. 69, no. 2, pp. 456-462, 2008. 
[14] V. Colao, G. Marino, and H.-K. Xu, "An iterative method for finding common solutions of equilibrium and fixed point problems," Journal of Mathematical Analysis and Applications, vol. 344, no. 1, pp. 340$352,2008$.

[15] A. Moudafi, "Viscosity approximation methods for fixed-points problems," Journal of Mathematical Analysis and Applications, vol. 241, no. 1, pp. 46-55, 2000.

[16] J. W. Peng, "Iterative algorithms for mixed equilibrium problems, strictly pseudocontractions and monotone mappings," Journal of Optimization Theory and Applications. In press.

[17] J. W. Peng, Y. C. Liou, and J. C. Yao, "An iterative algorithm combining viscosity method with parallel method for a generalized equilibrium problem and strict pseudocontractions," Fixed Point Theory and Applications, vol. 2009, Article ID 794178, 21 pages, 2009.

[18] Y. J. Cho, X. Qin, and J. I. Kang, "Convergence theorems based on hybrid methods for generalized equilibrium problems and fixed point problems," Nonlinear Analysis: Theory, Methods \& Applications, vol. 71, no. 9, pp. 4203-4214, 2009.

[19] F. E. Browder, "Convergence of approximants to fixed points of nonexpansive non-linear mappings in Banach spaces," Archive for Rational Mechanics and Analysis, vol. 24, pp. 82-90, 1967.

[20] Z. Opial, "Weak convergence of the sequence of successive approximations for nonexpansive mappings," Bulletin of the American Mathematical Society, vol. 73, pp. 591-597, 1967.

[21] W. Takahashi and M. Toyoda, "Weak convergence theorems for nonexpansive mappings and monotone mappings," Journal of Optimization Theory and Applications, vol. 118, no. 2, pp. 417-428, 2003.

[22] S. Takahashi and W. Takahashi, "Strong convergence theorem for a generalized equilibrium problem and a nonexpansive mapping in a Hilbert space," Nonlinear Analysis: Theory, Methods $\mathcal{E}$ Applications, vol. 69 , no. 3, pp. 1025-1033, 2008.

[23] M. Bianchi and S. Schaible, "Generalized monotone bifunctions and equilibrium problems," Journal of Optimization Theory and Applications, vol. 90, no. 1, pp. 31-43, 1996.

[24] E. Blum and W. Oettli, "From optimization and variational inequalities to equilibrium problems," The Mathematics Student, vol. 63, no. 1-4, pp. 123-145, 1994.

[25] P. L. Combettes and S. A. Hirstoaga, "Equilibrium programming in Hilbert spaces," Journal of Nonlinear and Convex Analysis, vol. 6, no. 1, pp. 117-136, 2005.

[26] A. Moudafi, "Weak convergence theorems for nonexpansive mappings and equilibrium problems," Journal of Nonlinear and Convex Analysis, vol. 9, no. 1, pp. 37-43, 2008.

[27] S. Wang, H. Zhou, and J. Song, "Viscosity approximation methods for equilibrium problems and fixed point problems of nonexpansive mappings and inverse-strongly monotone mappings," Methods and Applications of Analysis, vol. 14, no. 4, pp. 405-419, 2007.

[28] L.-C. Ceng and J.-C. Yao, "A hybrid iterative scheme for mixed equilibrium problems and fixed point problems," Journal of Computational and Applied Mathematics, vol. 214, no. 1, pp. 186-201, 2008.

[29] O. Chadli, Z. Chbani, and H. Riahi, "Equilibrium problems with generalized monotone bifunctions and applications to variational inequalities," Journal of Optimization Theory and Applications, vol. 105, no. 2, pp. 299-323, 2000.

[30] H. Brezis, Analyse Fonctionnelle, Collection Mathématiques Appliquées pour la Maîtrise, Masson, Paris, France, 1983. 